\title{
Seasonal distribution, risks, and sources of endocrine disrupting chemicals in coastal waters: Will these emerging contaminants pose potential risks in marine environment at continental-scale?
}

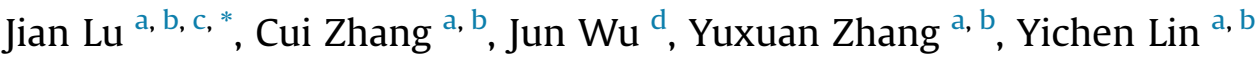 \\ ${ }^{a}$ CAS Key Laboratory of Coastal Environmental Processes and Ecological Remediation, Yantai Institute of Coastal Zone Research (YIC), Chinese Academy of \\ Sciences (CAS), Shandong Key Laboratory of Coastal Environmental Processes, YICCAS, Yantai, Shandong, 264003, PR China \\ ${ }^{\mathrm{b}}$ University of Chinese Academy of Sciences, Beijing, 100049, PR China \\ ' Center for Ocean Mega-Science, Chinese Academy of Sciences, 7 Nanhai Road, Qingdao, 266071, PR China \\ ${ }^{\mathrm{d}}$ School of Resources and Environmental Engineering, Ludong University, Yantai, Shandong, 264025, PR China
}

\section{H I G H L I G H T S}

- EDCs in coastal waters showed significant spatio-temporal variation.

- EDCs in coastal waters exerted high ecological risks.

- Average estradiol equivalent concentration of EDCs in winter/summer exceeded $1 \mathrm{ng} / \mathrm{L}$.

- Non-cancer risks posed by EDCs in coastal waters were negligible.

- Wastewater and sewage might be the main source for EDCs in coastal waters.

\section{A R T I C L E I N F O}

\section{Article history:}

Received 29 October 2019

Received in revised form

10 December 2019

Accepted 12 January 2020

Available online 14 January 2020

Handling Editor: Gang Cao

\section{Keywords:}

Endocrine disrupting chemicals

Coastal water

Risk assessment

Source apportionment

Estradiol equivalent concentration

Continental-scale
G R A P H I C A L A B S T R A C T

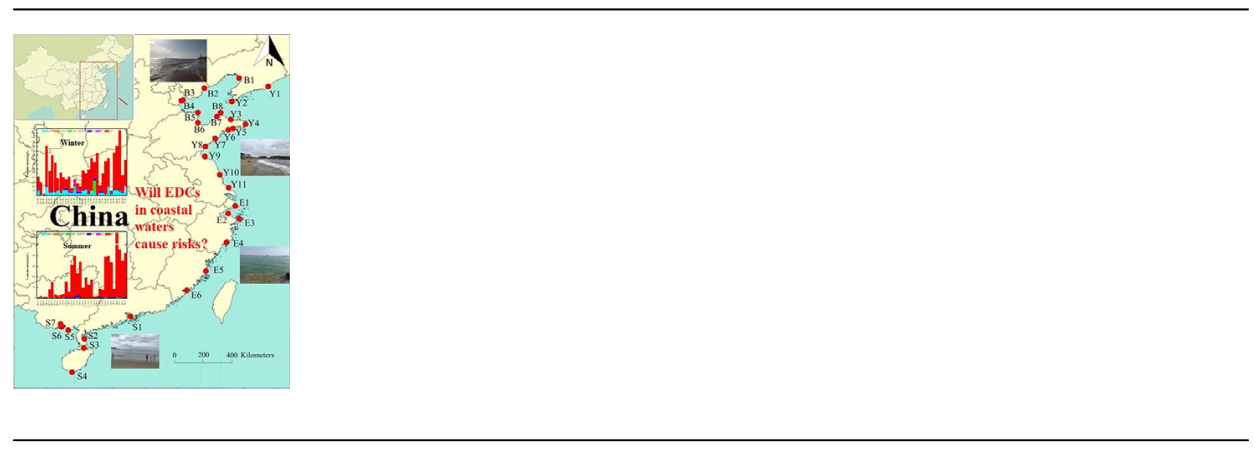

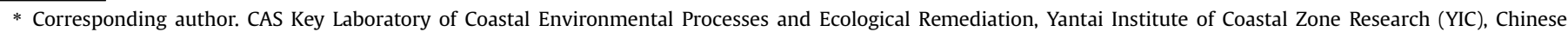
Academy of Sciences (CAS); Shandong Key Laboratory of Coastal Environmental Processes, YICCAS, Yantai, Shandong, 264003, PR China.

E-mail address: jlu@yic.ac.cn (J. Lu).
} 
highlighting that EDCs contamination has become a crucial stress affecting the sustainable development of coastal regions.

() 2020 Elsevier Ltd. All rights reserved.

\section{Introduction}

Coastal zone provides living environment for over $50 \%$ of human population in the world (Dennison, 2008). Coastal water is important for ecological safety and human health in coastal zone so that coastal water quality has attracted wide attention (Lu et al., 2018, 2019a,b; Pignotti and Dinelli, 2018). Coastal water pollution induced by different pollutants frequently occurs along coastline and shows significant spatial variation (Lu et al., 2018, 2019a; 2019b). However, information on distribution and risks of endocrine disrupting chemicals (EDCs) which are emerging contaminants to induce feminization of aquatic organisms even at $\mathrm{ng} / \mathrm{L}$ level (Hansen et al., 1998) in coastal water at continental-scale is not available. Most of studies mainly focused on occurrence of EDCs in a local coastal area only in a season (Lopes et al., 2016; Pignotti and Dinelli, 2018; Pojana et al., 2007).

EDCs generally include natural estrogens and synthesized chemicals showing estrogenic activity. Estrone (E1), estradiol (E2), and estriol (E3) are 3 steroidal estrogens naturally existing in human/animal bodies while 17 - $\alpha$-ethynylestradiol (EE2) is synthesized mainly for birth control (Lu et al., 2012). Bisphenol A (BPA), 4nonylphenol (4-NP), and 4-tert-octylphenol (4-t-OP) are environmental xenoestrogens synthesized with high production volume (Lu et al., 2012; Sheikh et al., 2017). EDCs widely exist in various matrices such as sediments, water, soils, air, and biota (Lu et al., 2012; Philip et al., 2018; Pojana et al., 2007), possibly posing potential risks to the ecosystems and human health.

Environmental pollution has become a crucial stress affecting the critical ecologically fragile regions such as the coastal zone due to the rapid economic development and extensive anthropogenic activities (Lu et al., 2018, 2019a, 2019b; Wu et al., 2019). Coastal waters are the critical ecologically fragile regions under the influence of the fastest economic developing pace and the extensive anthropogenic activities in coastal zone (Lu et al., 2018). Little information on the distribution, risks, and sources of endocrine disrupting chemicals (EDCs) in coastal waters at continental-scale is available. Source apportionment and risk assessment has become increasingly important for control of emerging contaminants including EDCs (Huang et al., 2012; Lu et al., 2019a). It is still not clear how the different sources contribute to EDCs in coastal waters. Therefore, this study performed field investigation, risk assessment, and source apportionment to discuss the distribution, potential risks, and possible sources of EDCs in coastal waters along the $18,000 \mathrm{~km}$ coastline of China during dry and wet seasons. The final objective is to provide new comprehensive information on the continental-scale distribution, risks, and sources of endocrine disrupting chemicals in coastal waters, which is of great importance on the effective management and control of EDCs contamination in coastal zone.

\section{Materials and methods}

\subsection{Sampling strategy, chemicals, and sample pretreatment}

Water samples were collected from 32 sites along the $18,000 \mathrm{~km}$ coastline of China in winter (November of 2017) and summer (June and July of 2018). The sampling sites belonged to Yellow Sea Area marked as Y, Bohai Area marked as B, and East/South China Sea Area marked as E/S (Fig. 1a). The most of sampling sites were close to the cities. Sampling strategy referred to the previous report (Lu et al., 2019a). Each water sample was composed of 6 sub-samples $(6 \times 5 \mathrm{~L})$. Measurement of total organic carbon (TOC), total phosphorus (TP), total nitrogen (TN), nitrate, nitrite, ammonium, phosphate, and silicate referred to the previous studies (Lu et al., 2018, 2019b). Coastal water samples were collected from Ningde (belonged to Fujian Province and near site E5), before (July 10, 2018) and after (July 16, 2018) the typhoon Maria and subjected to EDCs analysis in order to evaluate the effect of strong precipitation on the concentrations of target EDCs in coastal waters. The typhoon Maria reached the coastal zone of Ningde on July 11 and passed by on July 12 of 2018, which led to a precipitation about $180 \mathrm{~mm}$.

Standards of estrone with purity $>98 \%, 17-\beta$-estradiol (E2, purity $>97 \%$ ), estriol with purity of $98 \%$, EE2 with purity $>98 \%$, 4-nnonylphenol (4-n-NP, purity $>98 \%$ ), 4-t-OP with purity of $98.5 \%$, and BPA with purity $>99 \%$ were obtained from Sigma-Aldrich (St. Louis, MO, USA). Internal standards including estrone-D4 with purity of 99\% and BPA-D16 with purity of 98 atom\% D were also purchased from Sigma-Aldrich. Both N,O-bis(trimethylsilyl) trifluoroacetamide (BSTFA) and trimethylchlorosilane (TMCS) with purity $>98 \%$ were obtained from Alfa Aesar (Ward Hill, MA, USA). Methylene chloride and acetonitrile with HPLC (high performance liquid chromatography) grade were purchased from Merck (Germany).

Liquid-liquid extraction (LLE) was performed within $24 \mathrm{~h}$ of sampling. The water sample with volume of $1 \mathrm{~L}$ was poured into a pre-cleaned 2-L Teflon separatory funnel. The sample bottle was rinsed by $30 \mathrm{~mL}$ nanopure water and rinsate was added into the funnel. This step was repeated twice. Mixed solution of isotope internal standards (concentration of $5 \mathrm{mg} / \mathrm{L}$ ) with volume of $10 \mu \mathrm{L}$ was immediately added in water sample. Methylene chloride (30 mL) was added to the separatory funnel and the funnel was shaken for $10 \mathrm{~min}$ to collect the extracts. This extraction procedure was repeated twice. The methylene chloride extract was concentrated to about $1.5 \mathrm{~mL}$ in a water bath $\left(50{ }^{\circ} \mathrm{C}\right)$, and then passed through anhydrous sodium sulphate to remove water. The solution was evaporated to nearly dry by gentle nitrogen flow. Then $100 \mu \mathrm{L}$ of methylene chloride with $50 \mu \mathrm{L}$ of BSTFA (99\%) -TMCS (1\%) were added to the dried samples. The vials were sealed and heated at $70{ }^{\circ} \mathrm{C}$ for $2 \mathrm{~h}$. The derivatised samples were cool down to room temperature and analyzed by gas chromatography/mass spectrometer (GC/MS).

\subsection{Instrumental analysis and quality control}

EDCs in water samples were analyzed by Agilent 7820A GC system (Palo Alto, CA, USA) coupled to a M7 single quadrupole MS system (Persee Co., Beijing, China) equipping with a $30 \mathrm{~m}$ DB-5MS column (0.25 mm I. D, Agilent J\&W Scientific, Palo Alto, CA, USA). The injection volume was $1 \mu \mathrm{L}$ with splitless mode and carrier gas of helium (purity $>99.999 \%, 1.0 \mathrm{~mL} / \mathrm{min}$ ). The temperature program for column oven began at $50^{\circ} \mathrm{C}$ and kept for $1 \mathrm{~min}$, then increased to $120{ }^{\circ} \mathrm{C}$ at a rate of $20{ }^{\circ} \mathrm{C} / \mathrm{min}$ and kept for $3 \mathrm{~min}$, continually increased to $280^{\circ} \mathrm{C}$ at rate of $8^{\circ} \mathrm{C} / \mathrm{min}$, and finally kept for $10 \mathrm{~min}$. The total runtime was $37.5 \mathrm{~min}$, including a solvent delay time of 

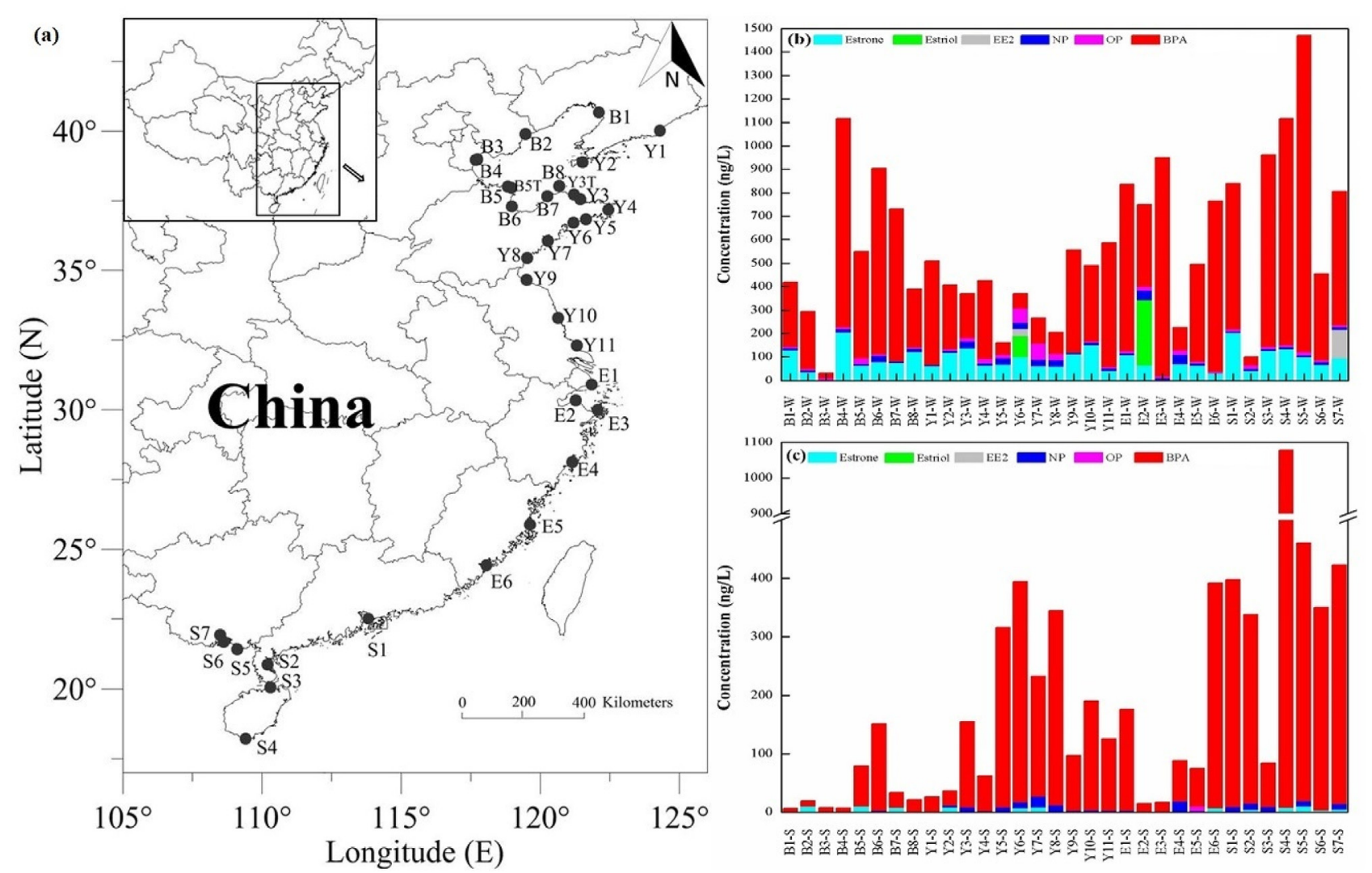

Fig. 1. Sampling sites (a) and concentrations of target EDCs in coastal waters during winter (b) and summer (c).

$14 \mathrm{~min}$. The temperatures of the injector, transfer line and ion source were held at $280{ }^{\circ} \mathrm{C}, 250{ }^{\circ} \mathrm{C}$ and $230{ }^{\circ} \mathrm{C}$, respectively. The confirmation and identification of target EDCs were based on their retention time and selected ion. Quantitative ions for 4-n-NP, 4-tOP, BPA-D16, BPA, estrone-D4, estrone, estradiol, estriol, and EE2 were $m / z$ 179, $m / z$ 207, $m / z$ 368, $m / z 357, m / z 346, m / z 342, m / z 416$, $m / z$ 311, and $m / z 368$, respectively. Qualitative ions for 4-n-NP, 4-tOP, BPA-D16, BPA, estrone-D4, estrone, estradiol, estriol, and EE2 were $m / z 292 / 220, m / z$ 278/208, $m / z 386 / 217, m / z 358 / 372, m / z 220 /$ $261, m / z 218 / 257, m / z 285 / 129, m / z 386 / 504$, and $m / z 285 / 207$, respectively.

Two pure-water blanks were analyzed for each analysis series and no target EDCs were detected. Two pure-water samples spiked by mixed solution of EDCs were extracted for every 5 real water samples to assure quality control. The recoveries of target EDCs ranged from $95.0 \%$ to $112.7 \%$ while the RSD values were in the range of $2.8 \%-6.6 \%$ to meet the quality-control requirements.

\subsection{Estradiol equivalent concentrations, risk assessment, and source apportionment of EDCs in coastal water}

Estradiol equivalent concentration (EEQ) of target EDCs in water was determined by the following equation (Sun et al., 2008):

$$
E E Q=\sum E E Q_{i}=\sum E E F_{i} \times M E C_{i}
$$

where $E E Q_{i}$ is the estradiol equivalent concentration of the individual target $E D C ; E E F_{i}$ is the estradiol equivalency factor of the individual target EDC. EEF value of estrone/estradiol/estriol/EE2/ $\mathrm{NP} / \mathrm{OP} / \mathrm{BPA}$ was $0.63 / 1.00 / 0.297 / 2.2 / 6.9 \times 10^{-4} / 9.3 \times 10^{-4} /$ $3.8 \times 10^{-4}$ (Canesi et al., 2007; Drewes et al., 2005; Sun et al., 2008;
Zhao et al., 2011).

Risk quotient $(R Q)$ used to evaluate ecological risks of EDCs in coastal waters referred to previous report (Lu et al., 2018). Acute risk quotient $\left(R Q_{A}\right)$ was calculated by the predicted no-effect concentration $\left(P N E C_{A}\right)$ derived from the half effective/lethal concentration $(E C 50 / L C 50)$ of target EDC. Chronic risk quotient $\left(R Q_{C}\right)$ was calculated by $P N E C_{C}$ derived from the no observable effect concentration of target EDC. Ecological risks could be categorized into 4 levels including insignificant (RQ $<0.01)$, low $(0.01<R Q \leq 0.1)$, medium $(0.1<\mathrm{RQ} \leq 1)$, and high (RQ $>1$ ) (Lu et al., 2018). PNEC values of target EDCs were shown in Table $\mathrm{S} 1$.

Hazard quotient $(H Q)$ was used to evaluate the potential noncancer risks of EDCs since carcinogenic potency factors of target EDCs were not proposed for cancer risk assessment. EDCs in coastal waters generally pose risks to humans through dermal contact and HQ was calculated according to previous report (Lu et al., 2018). Infants, children, teenagers, and adults were selected as target group for health risk assessment and the corresponding parameters referred to $\mathrm{Wu}$ et al. (2019). The other parameters used for noncancer risk assessment referred to Lu et al. (2018). The reference dose $(R f D)$ through oral exposure pathway was $5.00 \times 10^{-5} \mathrm{mg} /$ (kg.day) for estrone and estradiol (Song et al., 2018) while it was $8.00 \times 10^{-2} / 1.00 \times 10^{-2} / 6.48 \times 10^{-2} / 7.52 \times 10^{-2} / 6.00 \times 10^{-3} \mathrm{mg} /$ (kg. day) for estriol/EE2/NP/OP/BPA calculated by the equation (Lu et al., 2018).

All data were processed on OriginPro 8.0 (Northampton, MA, USA). Source apportionment for EDCs in coastal waters was conducted by positive matrix factorization (PMF). The inputs and uncertainty of PMF model referred to USEPA (2014) and summarized information referred to Supplementary Material. 


\section{Results}

\subsection{Coastline-based distribution of target EDCs in coastal waters at a continental-scale}

Target EDCs in coastal waters showed significant temporal variations at a continental-scale (Fig. 1b and c). EDCs in coastal waters generally possessed higher concentrations in winter. The average total concentration of all target EDCs in coastal waters reached $580.0 \mathrm{ng} / \mathrm{L}$ in winter and $193.6 \mathrm{ng} / \mathrm{L}$ in summer. Phenolic EDCs were the predominant EDCs detected in coastal waters, averagely accounting for $78.94 \% / 96.24 \%$ of total target EDCs in winter/summer. BPA was detected in all water samples with average concentration of $449.2 / 186.3 \mathrm{ng} / \mathrm{L}$ in winter/summer. Detection frequency of NP/ OP was more than $90.0 \%$ in winter but only $59.4 \% / 3.1 \%$ in summer. Concentrations of NP and OP in coastal waters were comparable in winter with the average concentration of 13.8 and $13.6 \mathrm{ng} / \mathrm{L}$, respectively. However, concentrations of NP in coastal waters were significantly higher than those of OP during summer. Estrone was the predominant steroidal estrogen with detection frequency of 93.75\%/37.50\% in winter/summer while estradiol was not detected in all coastal water samples. The maximal/average concentration of estrone reached 204.4/87.2 ng/L in winter and 9.8/2.7 ng/L in summer. Estriol was only detected in 2 samples in winter with high concentrations of 278.4 and $89.3 \mathrm{ng} / \mathrm{L}$ while EE2 was only detected in Y6 and S7 in winter with concentration of 29.8 and $120.7 \mathrm{ng} / \mathrm{L}$, respectively.

Target EDCs in coastal waters also showed significant spatial variations (Fig. 1 b and c). Total concentrations of all target EDCs and concentrations of BPA in coastal waters of South China Sea Area were significantly higher than those of the other areas, with the average total concentration of EDCs or BPA following the order of South China Sea Area $>$ East China Sea Area $>$ Bohai Area $>$ Yellow Sea Area in winter and South China Sea Area > Yellow Sea Area $>$ East China Sea Area $>$ Bohai Area in summer. NP in coastal water of East China Sea Area and South China Sea Area possessed higher concentrations than the other area in winter and summer, respectively. Concentrations of OP in water of Bohai Area were significantly higher than those in the other areas in winter while OP was only detected in E5 in summer with concentration of $7.2 \mathrm{ng} / \mathrm{L}$. Steroidal EDCs showed different spatial distribution feature with phenolic EDCs. Estrone existed in coastal waters of Bohai Area and Yellow Sea Area with the similar concentrations in both winter and summer. Average concentration of estrone in coastal waters followed the order of South China Sea Area > Yellow Sea Area > Bohai Area $>$ East China Sea Area in winter and South China Sea Area $>$ Bohai Area $>$ Yellow Sea Area $>$ East China Sea Area in summer. Estriol and EE2 were only detected in water of Yellow Sea Area and East or South China Sea Area in winter. In summary, coastal water of South China Sea Area possessed EDCs with higher concentrations than the other areas.

\subsection{Distribution of EDCs in coastal waters of different functional zones}

EDCs in coastal waters of different functional zones showed significant variations (Fig. 2). Average concentration of all target EDCs in coastal waters of bathing beaches was significantly higher than that of the other functional zones to reach $640.2 / 244.1 \mathrm{ng} / \mathrm{L}$ in winter/summer. Average concentration of all target EDCs in coastal waters followed the order of bathing beaches > estuaries $>$ ports $>$ maricultural zones in winter and bathing beaches $>$ maricultural zones $>$ ports $>$ estuaries in summer. Average concentration of estrone in coastal waters followed the order of estuaries $>$ maricultural zones $>$ ports $>$ bathing beaches while that of OP followed the opposite order in winter (Fig. 2a and b). The maximal average concentration of NP occurred in ports while that of BPA occurred in bathing beaches during both winter and summer (Fig. 2c and d). Steroidal estrogens generally existed in waters near estuaries with relatively high concentrations while concentrations of phenolic EDCs in coastal waters near ports and beaches were relatively high.

\subsection{Effect of strong precipitation on the concentrations of target EDCs in coastal waters}

The typhoons usually occur in summer in the coastal zone of Asia-Pacific area, which bring plenty of precipitation. The typhoon Maria brought strong precipitation in coastal zone of Ningde during July $11-12,2018$. Concentration of BPA decreased from 91.8 to $38.5 \mathrm{ng} / \mathrm{L}$ after the typhoon with strong precipitation while that of NP decreased from 3.2 to $2.9 \mathrm{ng} / \mathrm{L}$ (Fig. 3). Concentrations of both BPA and NP decreased sharply due to the strong precipitation with approximately $180 \mathrm{~mm}$ within 2 days. Meanwhile, other EDCs including OP and steroid hormones (estrone, estradiol, estriol, and EE2) were not detected. The results confirmed that the seasonal differences in the concentration of EDCs in the coastal waters might be influenced by the strong precipitation in the wet season (the summer).

\subsection{Estradiol equivalent concentrations of all target EDCs in coastal waters at a continental-scale}

EEQs of all target EDCs in coastal waters ranged from 0.02 (B3) to 326.27 (S7) ng/L in winter and from 0.002 (B1) to 6.19 (B5) in summer (Fig. 4a and b). Average EEQ of all target EDCs in coastal waters of South China Sea Area, Yellow Sea Area, Bohai Area, and East China Sea Area in winter/summer reached 107.35/2.78, 64.47/ 1.39, 55.96/2.11, and 49.29/0.78 ng/L, respectively. Estrone contributed to over $99.1 \%$ of total EEQs in water of $84.4 \%$ of sampling sites in winter while it contributed to more than $92.0 \%$ of total EEQs in coastal water of $37.5 \%$ of sampling sites. BPA contributed to $96.2 \%$ of total EEQs in water sample E3 in winter while it contributed to over $90.5 \%$ of total EEQs in water of 17 sites and $68.5 \%-82.1 \%$ of total EEQs in water of 3 sites during summer.

\subsection{Ecological risks of target EDCs in coastal waters at a continental-scale}

Ecological risks posed by EDCs in coastal waters showed significant spatio-temporal difference (Fig. 5). $R Q_{A}$ values of EDCs in coastal waters in winter were in the range of $21.5-1.36 \times 10^{5}$ with the mean value of $7.91 \times 10^{3}$ while those were in the range of $5.8-1.17 \times 10^{3}$ with the mean value of $2.64 \times 10^{2}$ in summer (Fig. $5 \mathrm{a}$ and c). $R Q_{C}$ values of EDCs in coastal waters in winter ranged from 31.4 to $4.73 \times 10^{4}$ with the mean value of $7.96 \times 10^{3}$ while those ranged from 5.9 to $1.57 \times 10^{3}$ with the mean value of $3.72 \times 10^{2}$ in summer (Fig. $5 \mathrm{~b}$ and d). Estrone averagely contributed to $61.42 \% /$ $81.95 \%$ of acute/chronic ecological risks in winter while average percentage of $R Q_{A} / R Q_{C}$ contributed by estrone decreased to $14.68 \% /$ $24.29 \%$ in summer although it caused $94.56 \% / 98.57 \%$ of total acute/ chronic ecological risks for B2. BPA averagely contributed to $23.95 \% /$ $11.65 \%$ and $71.95 \% / 73.27 \%$ of $R Q_{A} / R Q_{C}$ in winter and summer, respectively. Different from concentration distribution feature, acute ecological risks posed by EDCs in coastal waters of different areas followed the order of South China Sea Area $>$ Yellow Sea Area $>$ East China Sea Area $>$ Bohai Area and chronic ecological risks followed the order of South China Sea Area $>$ Yellow Sea Area $>$ Bohai Area $>$ East China Sea Area. Both acute and chronic ecological risks posed by EDCs in coastal waters of all sites were 

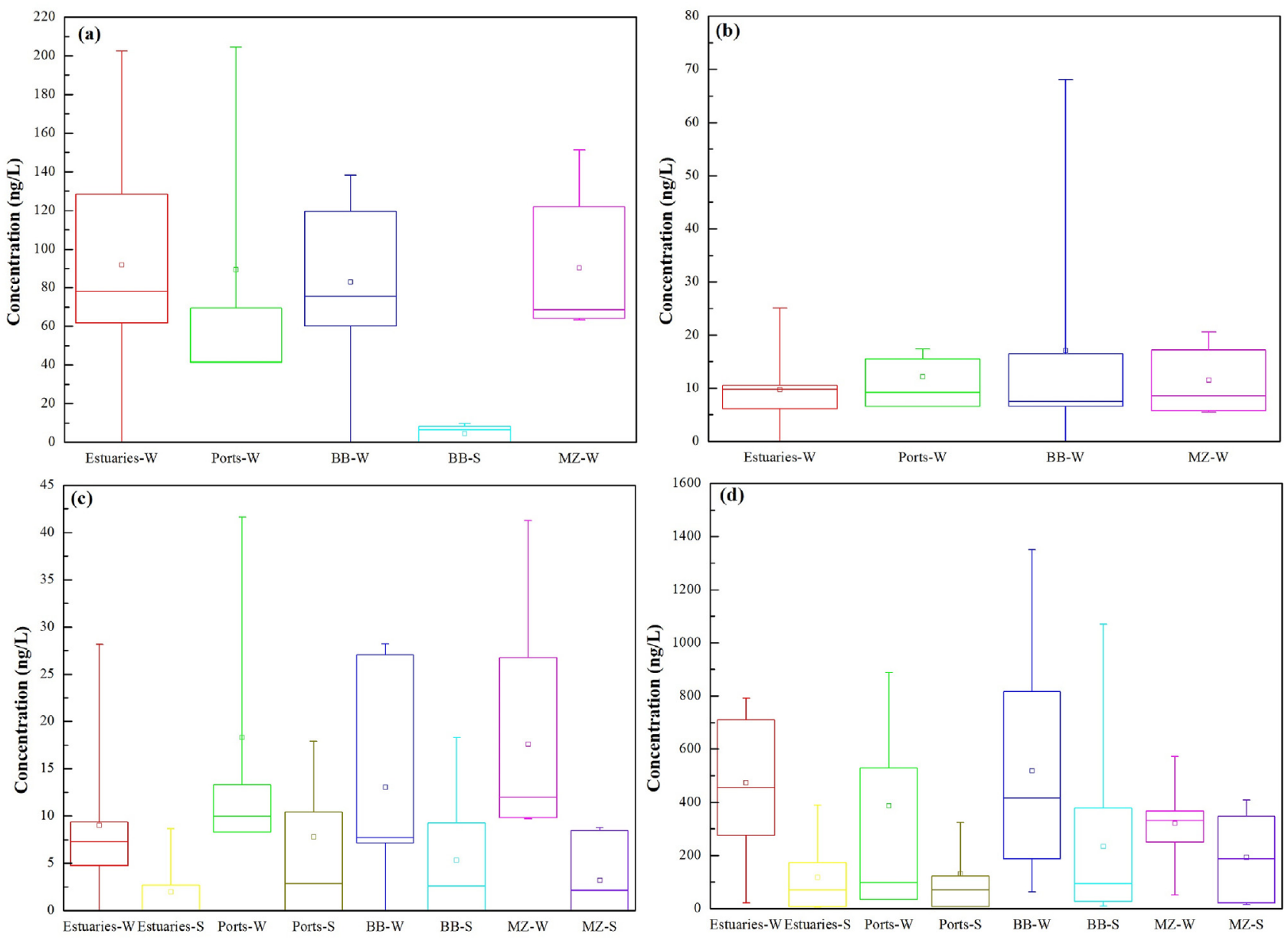

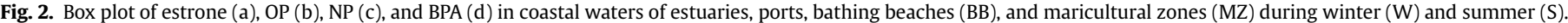

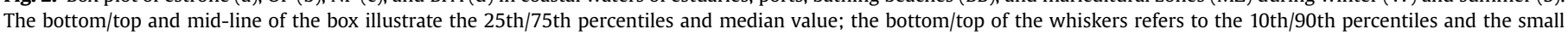
square inside each box stands for the average value.

high in winter and summer since all $R Q s$ were much higher than threshold of 1 .

\subsection{Health risks of target EDCs in coastal waters at a continental- scale}

$H Q s$ exerted by EDCs in coastal waters ranged from $1.83 \times 10^{-7}$ for male adults (B3) to $7.97 \times 10^{-4}$ for children (B4) in winter and from $5.01 \times 10^{-8}$ for male adults (B1) to $6.15 \times 10^{-5}$ for children (S4) in summer (Fig. 6a and b). HQs exerted by EDCs in coastal waters followed the order of children $>$ infants $>$ female adults $>$ female teenagers $>$ male teenagers $>$ male adults due to different surface areas and weights of different human groups. HQs of estrone accounted for $83.64 \%-99.34 \%$ of total HQs for $93.8 \%$ of sampling sites in winter while those covered $53.24 \%-99.19 \%$ of total HQs for $34.4 \%$ of sampling sites in summer. BPA contributed to $54.48 \%-100 \%$ of total $H Q$ s for $65.6 \%$ of sampling sites in summer. HQs of all target EDCs in coastal waters of different areas followed the order of South China Sea Area > Bohai Area > Yellow Sea Area > East China Sea Area in both winter and summer. HQs of all target EDCs in coastal waters of bathing beaches were in the range of $1.42 \times 10^{-7}-6.15 \times 10^{-5}$ in summer and $3.97 \times 10^{-5}-5.37 \times 10^{-4}$ in winter, higher than those in the other functional areas. All HQs were much lower than threshold of 1.0, illustrating that EDCs in coastal water would not cause potential non-cancer health risks to all human groups.

\subsection{Potential sources of target EDCs in coastal waters at a continental-scale}

PMF was used to identify possible sources of target EDCs in coastal waters along the coastline at a continental-scale (Fig. 7a and b). EDCs in coastal waters might be influenced by three possible sources including industrial wastewater (factor 1), mixture sources consisting of river inflows and degradation (factor 2), and domestic sewage \& breeding wastewater/tail water (factor 3 ). Approximately $89 \% / 97 \%$ of estrone in coastal waters during winter/summer was influenced by factor 2. Estradiol, estriol, and ethynylestradiol in winter coastal water might be mainly influenced by factor 3 (52\%$100 \%$ ) while those in summer coastal water were mainly influenced by factor 2 and factor 3 (54\%-99\%). Factor 2 and factor 3 were also main sources for NP/OP with total contribution proportion of $99 \%$ / $83 \%$ in winter. Approximately $97 \%$ of NP and $68 \%$ of OP in coastal water were affected by factor 3 during summer. Approximately $89 \% / 93 \%$ of BPA in coastal water was influenced by factor 1 in winter/summer. Wastewater and sewage were generally the main sources for EDCs in coastal waters of China, illustrating that EDCs in coastal water should be effectively eliminated if wastewater and sewage were further treated for removing EDCs.

The Pearson matrix of EDCs and water quality parameters also 


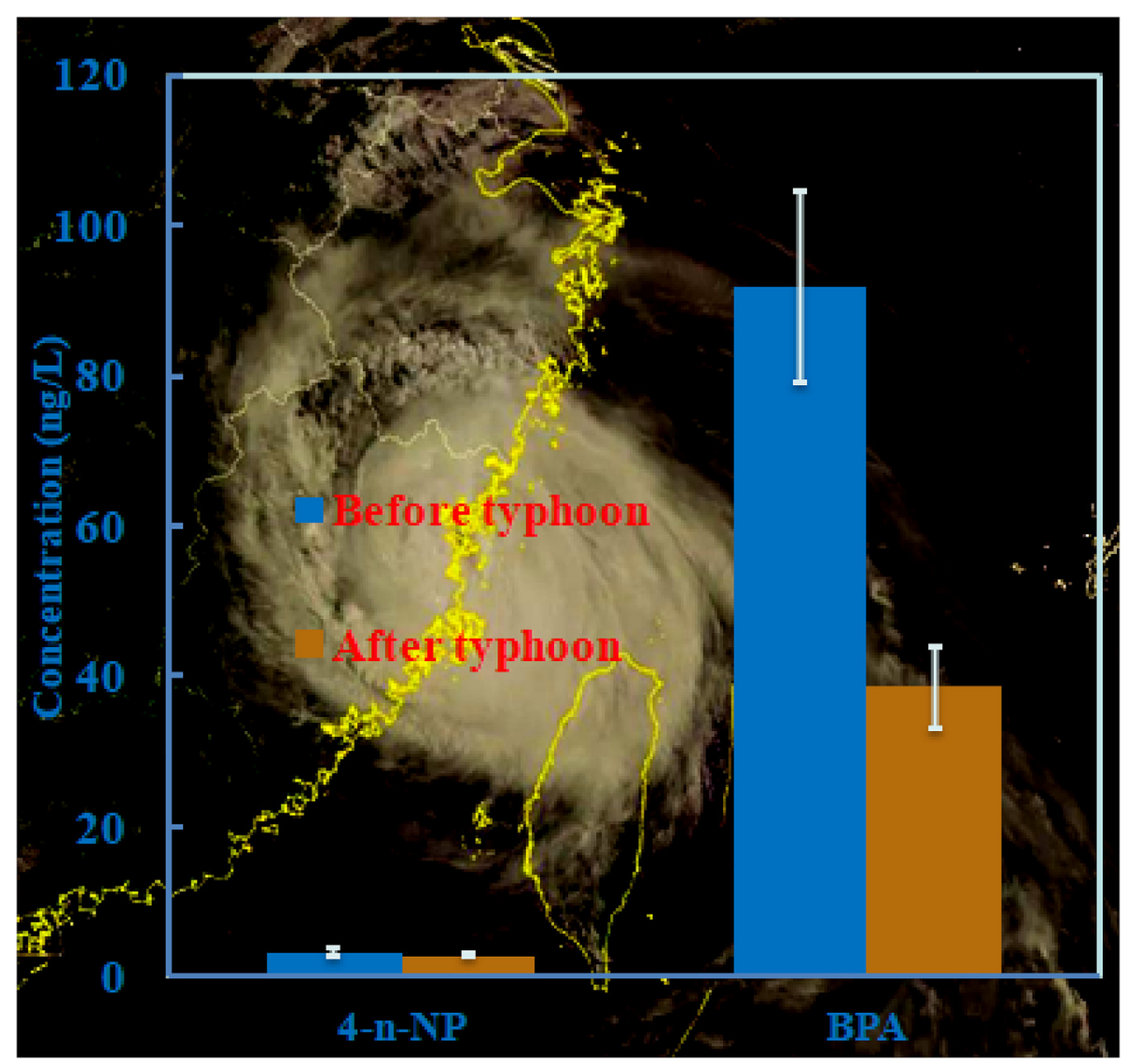

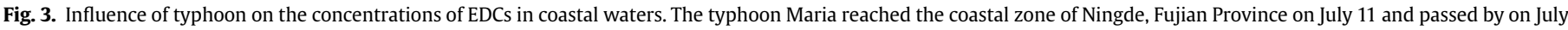

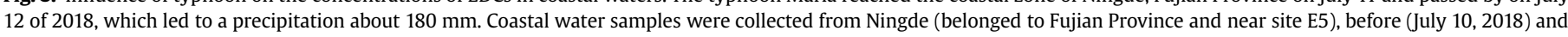
after (July 16, 2018).

indicated the close relationship between the wastewater discharge and EDCs. Estriol had significantly positive relationship with TOC while EE2 had significantly positive relationship with phosphate (Table S2). BPA had significantly positive relationship with ammonium and TP (Table S2). Estrone did not significantly relate with any water quality parameters, suggesting that other source (e.g. biodegradation) not wastewater discharge exerted main influence on estrone in coastal waters. Correlation analysis results generally confirmed the PMF source apportionment of EDCs in coastal waters.

\section{Discussion}

Comprehensive insight on EDCs contamination in coastal waters at a continental scale was obtained from this investigation. To the best of our knowledge, this was the first comprehensive study on EDCs in coastal environments in different seasons at a continental scale. Most of studies mainly focused on occurrence of EDCs in a local coastal area only in a season (Lopes et al., 2016; Pignotti and Dinelli, 2018; Pojana et al., 2007). According to the EEQs and ecological risk assessment at a continental-scale, EDCs in the coastal waters might jeopardize the coastal ecosystems. Estradiol equivalent concentration of $1 \mathrm{ng} / \mathrm{L}$ is regarded as threshold for evaluation of endocrine disrupting activity such as feminization of male fish (Hansen et al., 1998). EDCs in coastal water of approximately $90.6 \% / 37.5 \%$ of sampling sites might exert potential endocrine disrupting effect on the aquatic organisms in winter/summer. Average estradiol equivalent concentration of all target EDCs reached $68.87 / 1.76 \mathrm{ng} / \mathrm{L}$ in winter/summer. Both acute and chronic ecological risks posed by EDCs in coastal waters of all sites were high in winter and summer since all $R Q s$ were much higher than threshold of 1 . Meanwhile, all HQs were much lower than threshold of 1.0, illustrating that EDCs in coastal water would not cause potential non-cancer health risks to all human groups. It was safe for people to play on the bathing beaches based on very low health risks posed by EDCs in coastal waters. EDCs in coastal waters of different functional zones showed significant variations. Steroidal estrogens with relatively high estrogen activity generally existed in waters in mariculture zone or near estuaries with relatively high concentrations, which led to the relatively high risk of EDCs pollutions. Average estradiol equivalent concentration in the mariculture zone was $53.80 \mathrm{ng} / \mathrm{L}$ which was beyond $50 \mathrm{ng} / \mathrm{L}$, indicating extremely high potential thread of EDCs on the mariculture production and sustainability. Estuaries are generally important hatching and breeding regions for fishes (Zhu et al., 2017). Therefore, steroidal estrogens with relatively high average estradiol equivalent concentration of $29.44 \mathrm{ng} / \mathrm{L}$ in estuarine waters would bring serious potential threat to fish resources. EDCs in coastal waters showed high estradiol equivalent concentration and ecological risks at continental-scale. The seasonal differences in the concentration of EDCs in the coastal waters might be influenced by the strong precipitation in the wet season (the summer) since there is usually plenty of precipitation in the coastal zone of China in summer. The great influence of precipitation on the concentration of EDCs in the inland river or watershed had also been reported (Fairbairn et al., 2016; Wang et al., 2018). The occurrence of the 


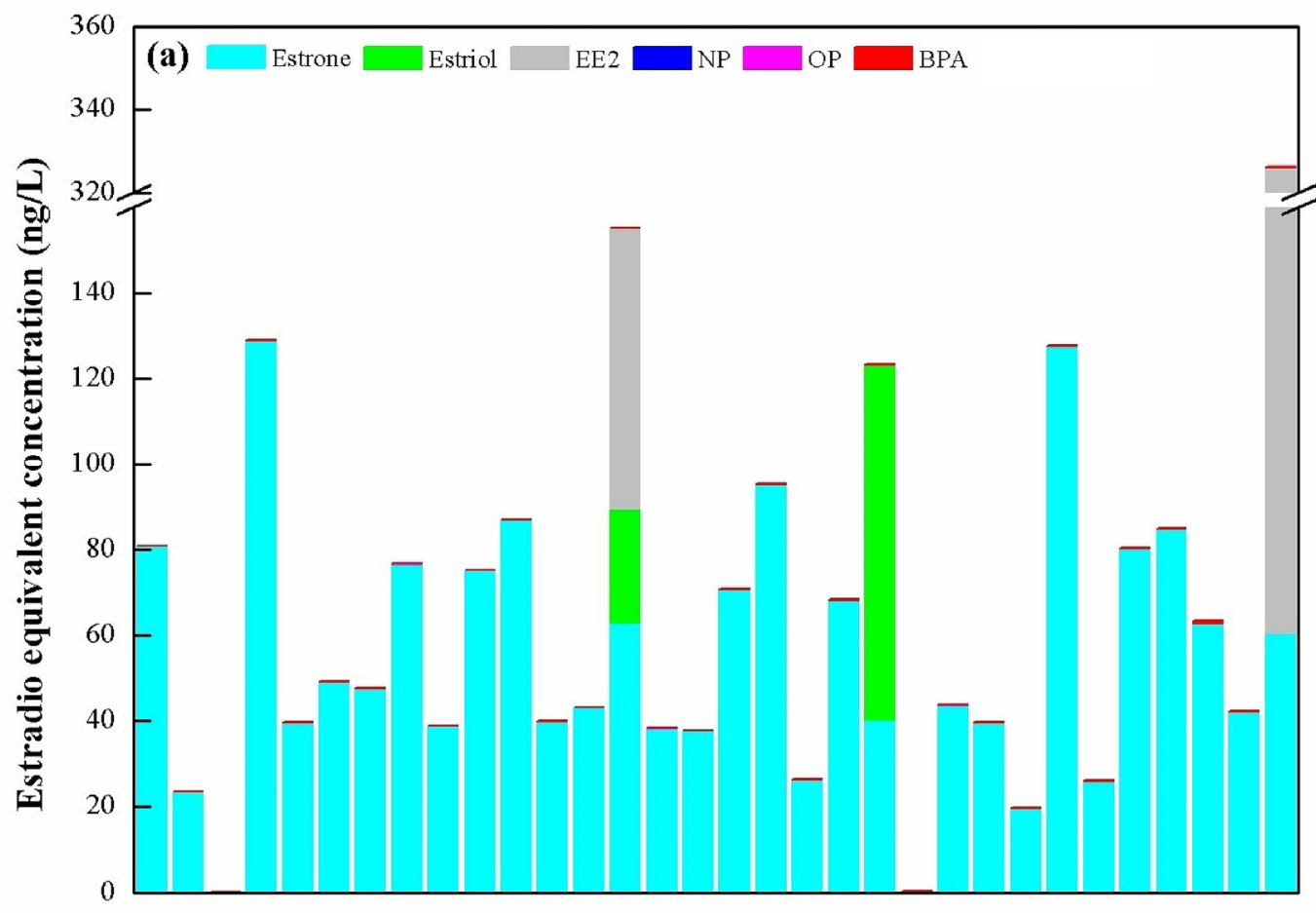

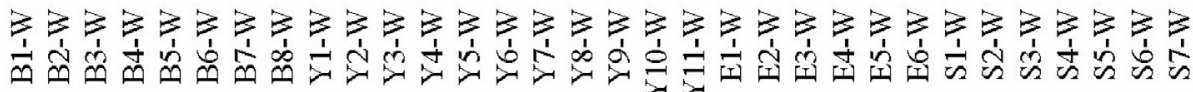

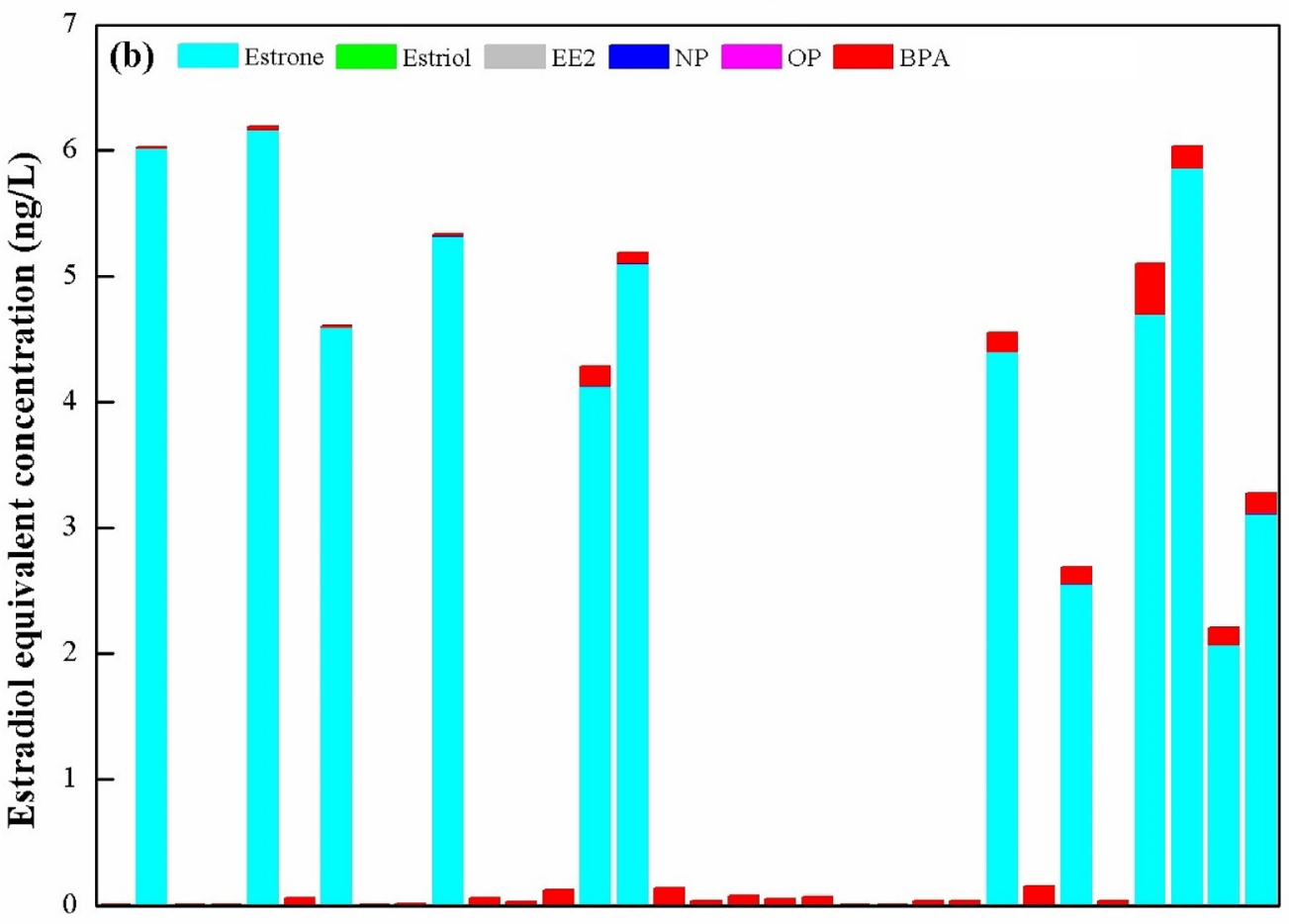

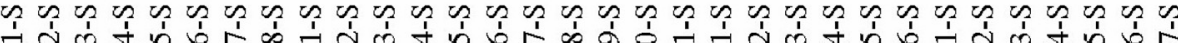

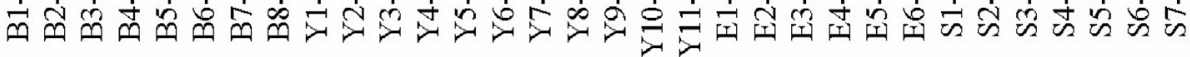

Fig. 4. Estradiol equivalent concentrations of target EDCs in coastal waters of China during winter (a) and summer (b). 

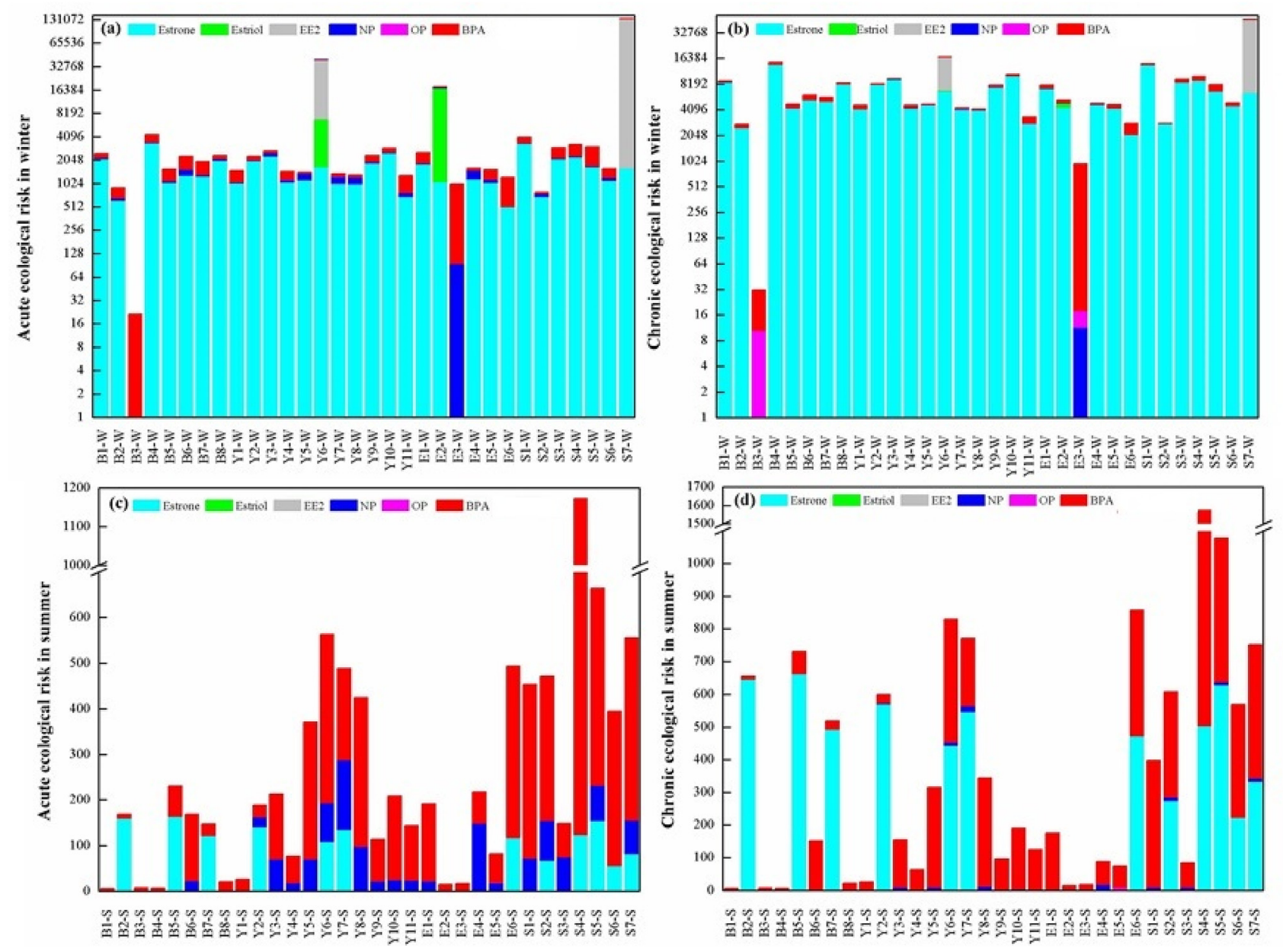

Fig. 5. Acute and chronic ecological risks of target EDCs in coastal waters in winter (a and b) and summer (c and d).

typhoon Maria led to the sharp decrease in the concentrations of EDCs in coastal waters, which also confirmed the significant effect of the precipitation on the concentrations of EDCs in coastal waters.

EDCs in coastal waters of some countries showed higher concentrations than those of China, illustrating that control of EDCs needs global attention and efforts. EDCs widely existed in coastal waters all over the world (Table 1 ). The maximal concentration of estrone/estriol in coastal water of Singapore reached 304/451 ng/L (Xu et al., 2011), much higher (nearly 1.5-1.6 times higher) than that of China. Except Singapore, concentrations of steroidal estrogens (not including estradiol) in coastal waters of other Asian countries were lower than those of this study. Estradiol was detected in coastal waters of other Asian countries with concentrations of 2.3-10.2 ng/L (Duong et al., 2010). Interestingly, concentrations of NP in coastal waters of other Asian countries (Basheer et al., 2004; Duong et al., 2010; Furuichi et al., 2004; Ko et al., 2007; Isobe et al., 2001; Xu et al., 2011) were much higher than those of China (this study). Maximal concentration of OP in coastal water of Japan/Singapore reached 180/800 ng/L (Basheer et al., 2004; Isobe et al., 2001), almost 2.6/11.7 times that of China. Concentrations of BPA in coastal water of Japan, Korea, and Singapore were higher than those of China (Basheer et al., 2004; Kashiwada et al., 2002; Ko et al., 2007). NP concentration in coastal water of the USA reached $420 \mathrm{ng} / \mathrm{L}$, almost 5 times highest NP concentration of this study. The maximal concentration of EE2/BPA in streams (including coastal streams) all over the USA reached 831/
$12,000 \mathrm{ng} / \mathrm{L}$ (Kolpin et al., 2002), much higher than that of EE2/BPA in China. Concentrations of estrone, estriol, EE2, NP, and OP in coastal waters of Brazil were lower than those of China while estradiol/BPA was detected with high frequency and the highest concentration of 18.2/39,860 ng/L in coastal waters of Brazil (Lisboa et al., 2013; Lopes et al., 2016). Estradiol was detected with relatively high concentrations in coastal waters of European countries (Camacho-Muñoz et al., 2010; Hibberd et al., 2009; Pojana et al., 2007). Concentrations of estriol, EE2, NP, and OP in coastal water of Spain were higher than those of China (Camacho-Muñoz et al., 2010; Salgueiro-González et al., 2012). The maximal concentration of NP in coastal water of UK, Germany, and Italy was higher than that of China (Diehl et al., 2012; Pojana et al., 2007). Although concentrations of steroidal estrogens in coastal water of these countries were lower than those of China, concentrations of phenolic EDCs in coastal water of Australia and Nigeria were higher than those of China (Oketola and Fagbemigun, 2013; Ying et al., 2009). EDCs with frequent detection and relatively high concentrations in coastal waters might have been exerting potential negative effects on global coastal ecosystem and human wellbeings. Therefore, the effective strategies should be put forward to control EDCs in global coastal waters.

Although source apportionment has become increasingly important for control of emerging contaminants including EDCs (Huang et al., 2012; Lu et al., 2019a), information on how the different sources contribute to EDCs in coastal waters is still not 


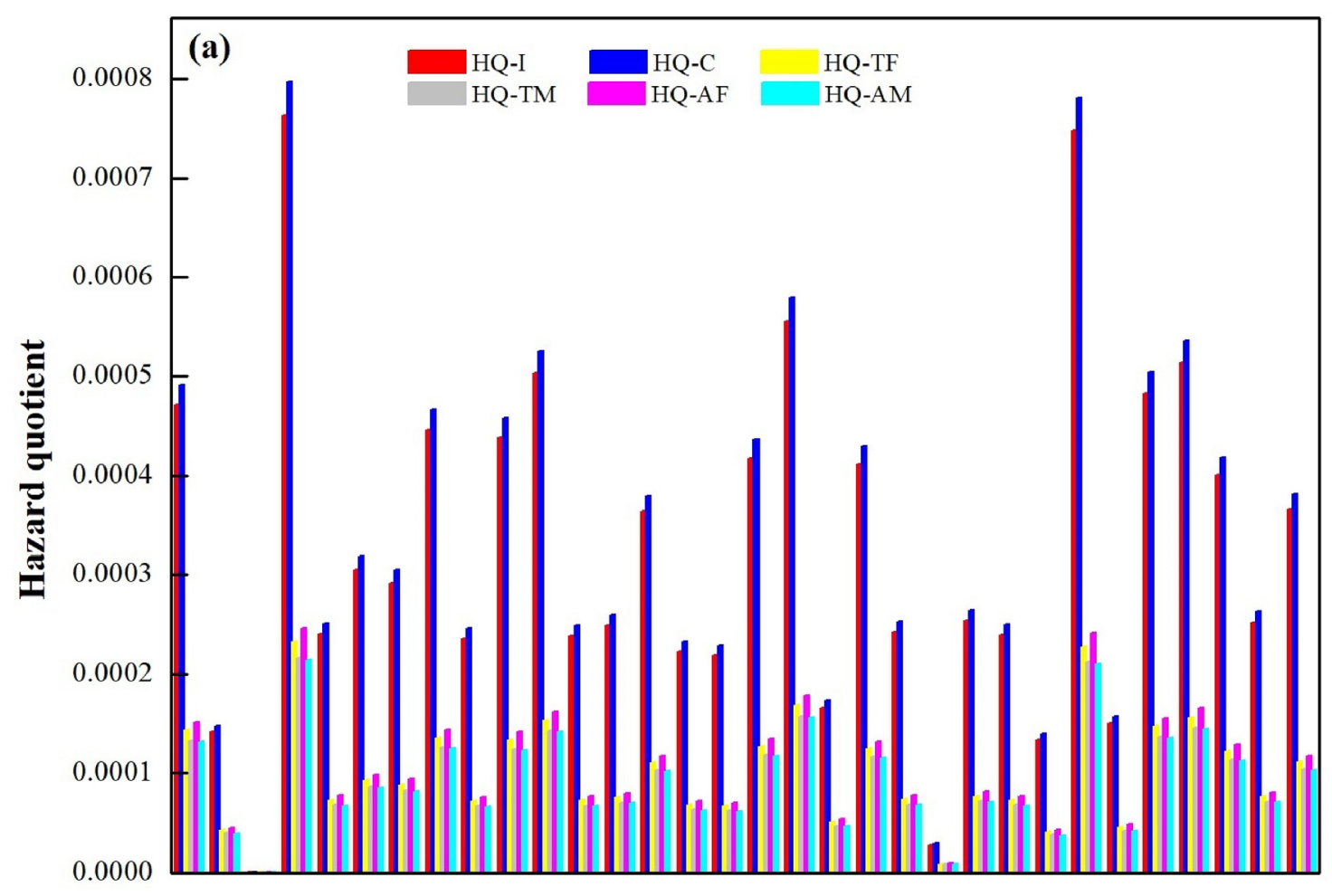

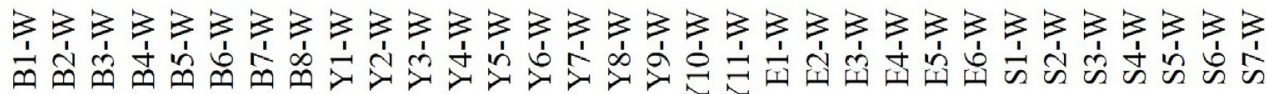

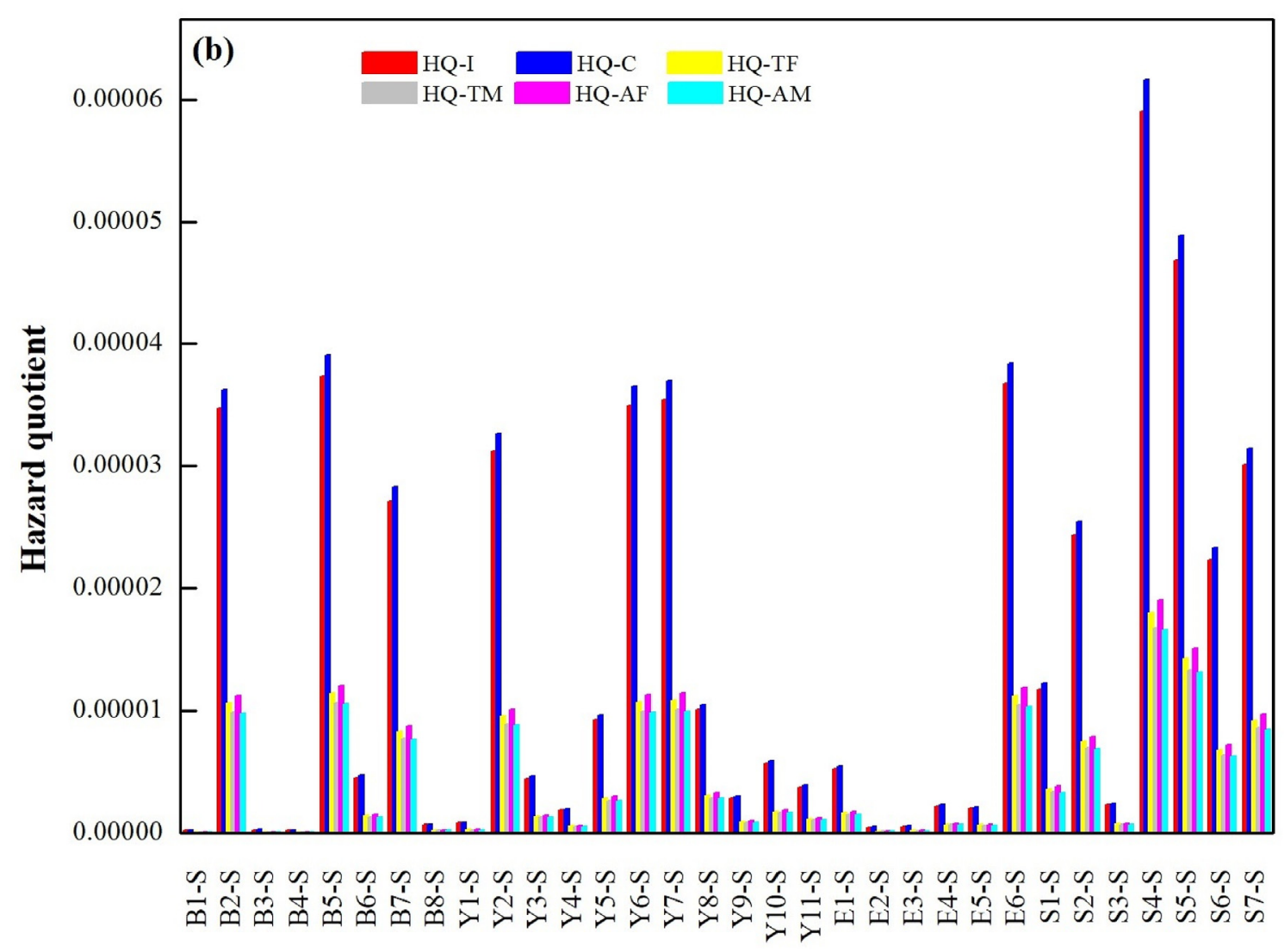

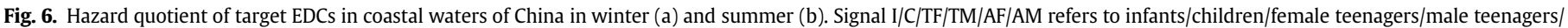
female adults/male adults. 


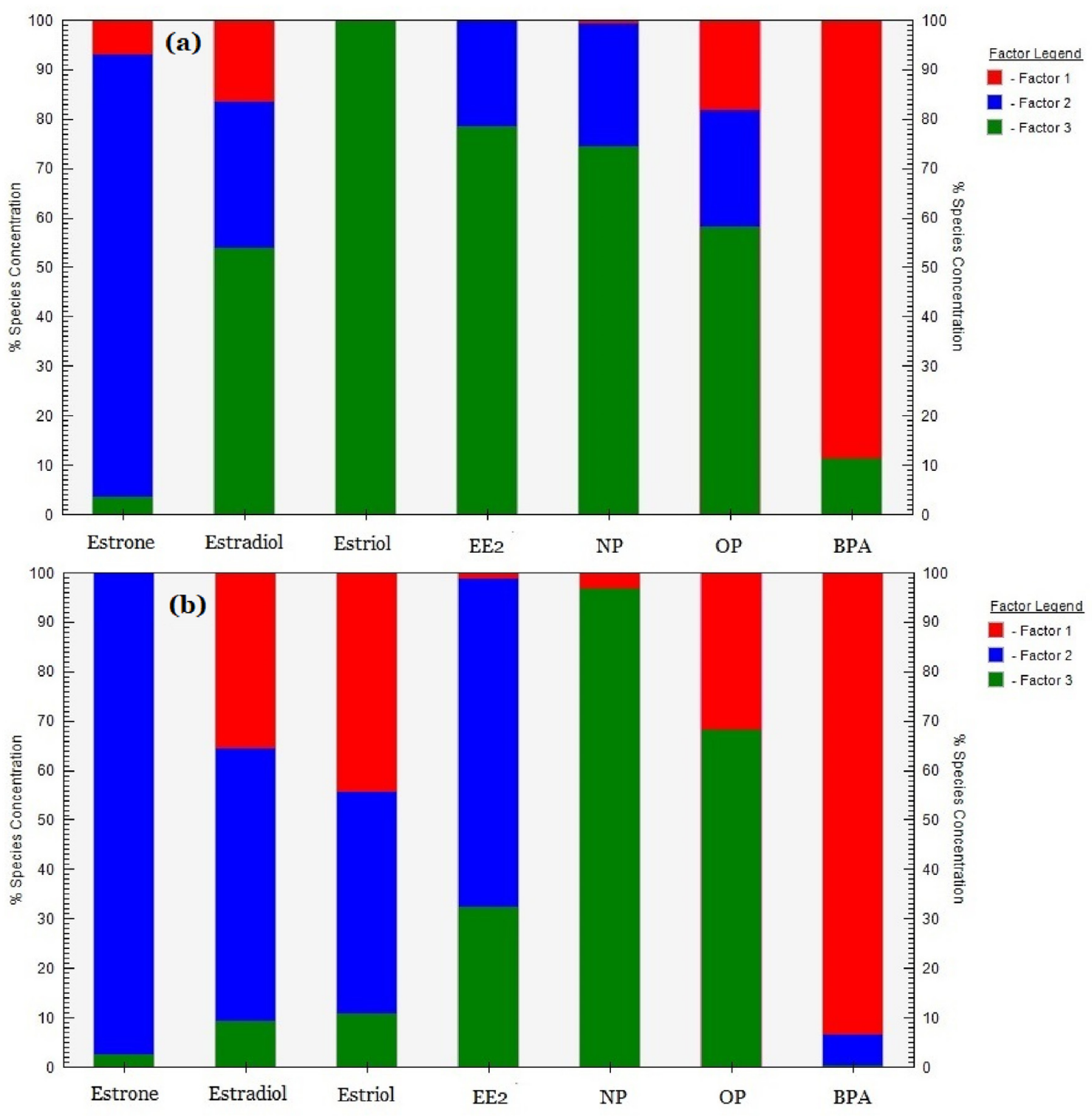

Fig. 7. Potential sources of target EDCs in coastal waters during winter (a) and summer (b) based on positive matrix factorization (PMF) model.

clear. The PMF model was a powerful model for quantifying the contribution of potential sources during source apportionment of pollutants (Lu et al., 2018). In this investigation, the PMF model was firstly used to identify possible sources of EDCs in coastal waters. EDCs in coastal waters could be affected by three possible sources including industrial wastewater, mixture sources consisting of river inflows and degradation, and sewage \& wastewater/tail water. The sewage \& wastewater/tail water have been considered as the main pollution source of EDCs (Lu et al., 2008; Ying et al., 2009). The coastal waters near ports and beaches might mainly be polluted through industrial water since concentrations of phenolic EDCs in coastal waters near ports and beaches were relatively high. Industrial water has been recognized as one of the main pollution source of phenolic EDCs (Lu et al., 2008; Wang et al., 2012). In the case of the river estuary, the mixed source might be the main pollutions sources. Similar results were also observed for the antibiotic pollution in the coastal waters (Lu et al., 2018). Input of different sources of EDCs might have seasonal variation so that the distribution of EDCs was also partially influenced by that.

\section{Conclusions}

Target EDCs in coastal waters showed significant spatiotemporal variation in coastal waters along continental-scale coastline. Phenolic chemicals were the dominant EDCs in coastal waters and BPA was detected in all water samples in both winter and summer with relatively high concentrations. Estrone was the predominant steroidal EDC detected in coastal water samples. EDCs in coastal waters posed very high ecological risks with estrone/BPA serving as the predominant risk contributor in winter/summer. Average EEQ of EDCs in coastal water during winter and summer exceeded $1.0 \mathrm{ng} / \mathrm{L}$ to have potential endocrine disrupting effect on the aquatic organisms while EDCs would not induce potential noncancer risks for humans. Wastewater and sewage might be the main source for EDCs in coastal water based on PMF analysis. EDCs in coastal waters demonstrated high estradiol equivalent concentration and ecological risks at continental-scale, highlighting that EDCs contamination might be a crucial stress affecting the sustainable development of coastal regions. Effective control of EDCs 
Table 1

Distribution of EDCs in coastal waters of different countries (concentration unit: ng/L).

\begin{tabular}{|c|c|c|c|c|c|c|c|c|}
\hline & Estrone & Estradiol & Estriol & EE2 & NP & $\mathrm{OP}$ & BPA & References \\
\hline China & ND-204.4 & ND & ND-278.4 & ND-120.7 & ND-41.6 & ND-68.1 & $20.9-1350.0$ & 1 \\
\hline Japan & $17.1-47.6$ & $2.6-7.7$ & $<0.2$ & $<0.2$ & $50-1080$ & $10-180$ & ND-1400 & $2,3,4$ \\
\hline Korea & $2.3-12.2$ & $4-5.6$ & NR & BDL-4.5 & ND-244800 & $0.1-3.3$ & ND-39400 & 5,6 \\
\hline Singapore & $<1-304$ & NR & $<3-451$ & NR & $20-2760$ & ND-800 & ND-2470 & 7,8 \\
\hline Indonesia & $6.8-77.5$ & $6.2-6.4$ & NR & $6-9.1$ & $39.3-238.5$ & BDL-2.1 & $7.6-7.8$ & 5 \\
\hline Malaysia & $4.4-6.5$ & $2.3-3.2$ & NR & $4.3-8.6$ & $134.9-814.4$ & $8.3-15.1$ & $7.4-10.8$ & 5 \\
\hline Vietnam & $4.6-62.4$ & $8.1-10.2$ & NR & $26.8-28.6$ & 1761.9-2097.4 & BDL-4.4 & $24.2-132.5$ & 5 \\
\hline USA & ND-112 & ND-93a & ND-51 ${ }^{\mathrm{a}}$ & ND-831 & ND-40000 $; 420$ & NR & ND-12000 & $9,10^{\mathrm{a}}$ \\
\hline Brazil & $<23$ & $<3.0-18.2$ & $<2.8-37.9$ & $<2.0$ & $<4.0$ & $<13$ & $1370-39,860$ & 11,12 \\
\hline UK & $0.6-14.3$ & $3.1-21.4$ & NR & ND-1.5 & $100-2600$ & ND-37.6 & ND-69.3 & 9,13 \\
\hline Germany & $0.1-4.1^{\mathrm{a}}$ & $0.15-3.6^{a}$ & NR & $0.1-5.1^{\mathrm{a}}$ & $0.3-84$ & $0.02-18$ & ND-249 & 14,15 \\
\hline Italy & $<1.2-10$ & $<1.0-175$ & NR & $<0.8-28$ & $<0.5-211$ & NR & $<1.0-145$ & 16 \\
\hline Spain & $<$ LOD & $<$ LOD-120 & $<$ LOD-480 & $<$ LOD-280 & ND-59 & ND-110 & ND-35 & 17,18 \\
\hline Australia & $1.14-20.91$ & $0.54-3.77$ & NR & $0.04-0.52$ & $367-1053$ & $13-94$ & $4-59$ & 19 \\
\hline Nigeria & NR & NR & NR & NR & $43.9-79.4$ & $57.1-68.6$ & ND- $<$ LOQ & 20 \\
\hline
\end{tabular}

Note:

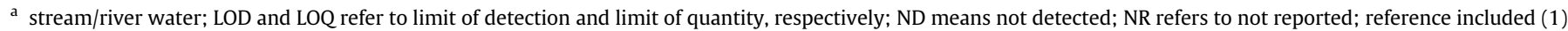

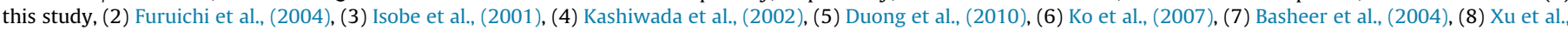

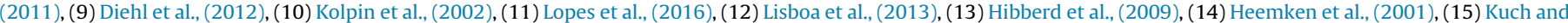

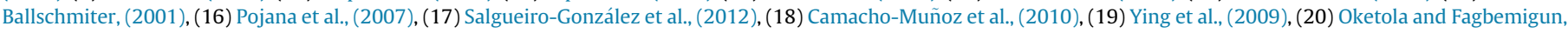
(2013).

contamination in coastal zone needed worldwide attention and efforts.

\section{Acknowledgements}

This work was supported by National Natural Science Foundation of China (41671319), Taishan Scholar Program of Shandong Province (No. tsqn201812116), One Hundred Talents Program of Chinese Academy of Sciences (Y629041021), and Two-Hundred Talents Plan of Yantai (Y739011021). The authors would like to thank the reviewers for their valuable suggestions and comments on the manuscript.

\section{Appendix A. Supplementary data}

Supplementary data to this article can be found online at https://doi.org/10.1016/j.chemosphere.2020.125907.

\section{References}

Basheer, C., Lee, H.K., Tan, K.S., 2004. Endocrine disrupting alkylphenols and bisphenol-A in coastal waters and supermarket seafood from Singapore. Mar. Pollut. Bull. 48, 1145-1167.

Camacho-Muñoz, D., Martín, J., Santos, J.L., Aparicio, I., Alonso, E., 2010. Occurrence, temporal evolution and risk assessment of pharmaceutically active compounds in Donana Park (Spain). J. Hazard Mater. 183, 602-608.

Canesi, L., Lorusso, L.C., Ciacci, C., Betti, M., Rocchi, M., Pojana, G., Marcomini, A. 2007. Immunomodulation of Mytilus hemocytes by individual estrogenic chemicals and environmentally relevant mixtures of estrogens: in vitro and in vivo studies. Aquat. Toxicol. 81, 36-44.

Dennison, W.C., 2008. Environmental problem solving in coastal ecosystems: a paradigm shift to sustainability. Estuar. Coast Shelf Sci. 77, 185-196.

Diehl, J., Johnson, S.E., Xia, K., West, A., Tomanek, L., 2012. The distribution of 4nonylphenol in marine organisms of North American Pacific Coast estuaries. Chemosphere 87, 490-497.

Drewes, J.E., Hemming, J., Ladenburger, S.J., Schauer, J., Sonzogni, W., 2005. An assessment of endocrine disrupting activity changes during wastewater treatment through the use of bioassays and chemical measurements. Water Environ. Res. 77, 12-23.

Duong, C.N., Ra, J.S., Cho, J., Kim, S.D., Choi, H.K., Park, J.-H., Kim, K.W., Inam, E., Kim, S.D., 2010. Estrogenic chemicals and estrogenicity in river waters of South Korea and seven Asian countries. Chemosphere 78, 286-293.

Fairbairn, DJ. Karpuzcu, M.E. Arnold, WA Barber, B.L, Kaufenberg E.F. Koskinen, W.C., Novak, P.J., Rice, P.J., Swackhamer, D.L., 2016. Sources and transport of contaminants of emerging concern: a two-year study of occurrence and spatiotemporal variation in a mixed land use watershed. Sci. Total Environ. $551-552,605-613$.

Furuichi, T., Kannan, K., Giesy, J.P., Masunaga, S., 2004. Contribution of known endocrine disrupting substances to the estrogenic activity in Tama River water samples from Japan using instrumental analysis and in vitro reporter gene assay. Water Res. 38, 4491-4501.

Hansen, P.-D., Dizer, H., Hock, B., Marx, A., Sherry, J., McMaster, M., Blaise, Ch, 1998. Vitellogenin-a biomarker for endocrine disruptors. Trac. Trends Anal. Chem. 17, $448-451$.

Heemken, O.P., Reincke, H., Stachel, B., Theobald, N., 2001. The occurrence of xenoestrogens in the Elbe river and the North Sea. Chemosphere 45, 245-259.

Hibberd, A., Maskaoui, K., Zhang, Z., Zhou, J.L., 2009. An improved method for the simultaneous analysis of phenolic and steroidal estrogens in water and sediment. Talanta 77, 1315-1321.

Huang, Y.Q., Wong, C.K.C., Zheng, J.S., Bouwman, H., Barra, R., Wahlström, B., Neretin, L., Wong, M.H., 2012. Bisphenol A (BPA) in China: a review of sources, environmental levels, and potential human health impacts. Environ. Int. 42, 91-99.

Isobe, T., Nishiyama, H., Nakashima, A., Takada, H., 2001. Distribution and behavior of nonylphenol, octylphenol, and nonylphenol monoethoxylate in Tokyo metropolitan area: their association with aquatic particles and sedimentary distributions. Environ. Sci. Technol. 35, 1041-1049.

Kashiwada, S., Ishikawa, H., Miyamoto, N., Ohnishi, Y., Magar, Y., 2002. Fish test for endocrine-disruption and estimation of water quality of Japanese rivers. Water Res. 36, 2161-2166.

Ko, E.-J., Kim, K.-W., Kang, S.-Y., Kim, S.-D., Bang, S.-B., Hamm, S.-Y., Kim, D.-W., 2007. Monitoring of environmental phenolic endocrine disrupting compounds in treatment effluents and river waters, Korea. Talanta 73, 674-683.

Kolpin, D.W., Furlong, E.T., Meyer, M.T., Thurman, E.M., Zaugg, S.D., Barber, L.B. Buxton, H.T., 2002. Pharmaceuticals, hormones, and other organic wastewater contaminants in U.S. Streams, 1999-2000: A national reconnaissance. Environ. Sci. Technol. 36, 1202-1211.

Kuch, H.M., Ballschmiter, K., 2001. Determination of endocrine-disrupting phenolic compounds and estrogens in surface and drinking water by HRGC-(NCI)-MS in the picogram per liter range. Environ. Sci. Technol. 35, 3201-3206.

Lisboa, N.S., Fahning, C.S., Cotrim, G., dos Anjos, J.P., de Andrade, J.B., Hatje, V., da Rocha, G.O., 2013. A simple and sensitive UFLC-fluorescence method for endocrine disrupters determination in marine waters. Talanta 117, 168-175.

Lopes, V.S.A., Riente, R.R., da Silva, A.A., Torquilho, D.F., Carreira, R.D.S. Marques, M.R.D.C., 2016. Development of a solid-phase extraction system modified for preconcentration of emerging contaminants in large sample volumes from rivers of the lagoon system in the city of Rio de Janeiro, Brazil. Mar. Pollut. Bull. 110, 572-577.

Lu, J., Jin, Q., He, Y., Wu, J., Zhang, W., Zhao, J., 2008. Biodegradation of nonylphenol polyethoxylates by denitrifying activated sludge. Water Res. 42, 1075-1082.

Lu, J., Wu, J., Stoffella, P.J., Wilson, P.C., 2012. Isotope dilution-gas chromatography mass spectrometry method for the analysis of alkylphenols, bisphenol $\mathrm{A}$, and estrogens in food crops. J. Chromatogr. A 1258, 128-135.

Lu, J., Wu, J., Zhang, C., Zhang, Y., Lin, Y., Luo, Y., 2018. Occurrence, distribution, and ecological-health risks of selected antibiotics in coastal waters along the coastline of China. Sci. Total Environ. 644, 1469-1476.

Lu, J., Zhang, C., Wu, J., Lin, Y., Zhang, Y., Yu, X., Zhang, Z., 2019a. Pollution, sources, and ecological-health risks of polycyclic aromatic hydrocarbons in coastal waters along coastline of China. Hum. Ecol. Risk Assess. https://doi.org/10.1080/ 10807039.2018.1548899, 2019.

Lu, J., Zhang, Y., Wu, J., Wang, J., Zhang, C., Lin, Y., 2019b. Occurrence and spatial distribution of antibiotic resistance genes in the Bohai Sea and Yellow Sea areas, China. Environ. Pollut. 252, 450-460.

Oketola, A.A., Fagbemigun, T.K., 2013. Determination of nonylphenol, octylphenol 
and bisphenol-A in water and sediments of two major rivers in lagos, Nigeria. J. Environ. Prot. 4, 38-45.

Philip, J.M., Aravind, U.K., Aravindakumar, C.T., 2018. Emerging contaminants in Indian environmental matrices - a review. Chemosphere 190, 307-326.

Pignotti, E., Dinelli, E., 2018. Distribution and partition of endocrine disrupting compounds in water and sediment: case study of the Romagna area (North Italy). J. Geochem. Explor. 195, 66-77.

Pojana, G., Gomiero, A., Jonkers, N., Marcomini, A., 2007. Natural and synthetic endocrine disrupting compounds (EDCs) in water, sediment and biota of a coastal lagoon. Environ. Int. 33, 929-936.

Salgueiro-González, N., Concha-Graña, E., Turnes-Carou, I., Muniategui-Lorenzo, S., López-Mahía, P., Prada-Rodríguez, D., 2012. Determination of alkylphenols and bisphenol $\mathrm{A}$ in seawater samples by dispersive liquid-liquid microextraction and liquid chromatography tandem mass spectrometry for compliance with environmental quality standards (Directive 2008/105/EC). J. Chromatogr. A $1223,1-8$.

Sheikh, I.A., Tayubi, I.A., Ahmad, E., Ganaie, M.A., Bajouh, O.S., AlBasri, S.F., Abdulkarim, I.M.J., Beg, M.A., 2017. Computational insights into the molecular interactions of environmental xenoestrogens 4-tert-octylphenol, 4nonylphenol, bisphenol A (BPA), and BPA metabolite, 4-methyl-2, 4-bis (4hydroxyphenyl) pent-1-ene (MBP) with human sex hormone-binding globulin. Ecotoxicol. Environ. Saf. 135, 284-291.

Song, X., Wen, Y., Wang, Y. Adeel, M., Yang, Y., 2018. Environmental risk assessment of the emerging EDCs contaminants from rural soil and aqueous sources: analytical and modelling approaches. Chemosphere 198, 546-555.

Sun, Q., Deng, S., Huang, J., Shen, G., Yu, G., 2008. Contributors to estrogenic activity in wastewater from a large wastewater treatment plant in Beijing, China.
Environ. Toxicol. Pharmacol. 25, 20-26.

USEPA (U.S. Environmental Protection Agency), 2014. EPA Positive Matrix Factorization (PMF) 5.0 Fundamentals and User Guide. EPA/600/R-14/108.

Wang, B., Huang, B., Jin, W., Wang, Y., Zhao, S., Li, F., Hu, P., Pan, X., 2012. Seasona distribution, source investigation and vertical profile of phenolic endocrine disrupting compounds in Dianchi Lake, China. J. Environ. Monit. 14, 1274-1281.

Wang, S., Zhu, Z., He, J., Yue, X., Pan, J., Wang, Z., 2018. Steroidal and phenolic endocrine disrupting chemicals (EDCs) in surface water of Bahe River, China: distribution, bioaccumulation, risk assessment and estrogenic effect on Hemiculter leucisculus. Environ. Pollut. 243, 103-114.

Wu, J., Lu, J., Wen, X., Zhang, Z., Lin, Y., 2019. Severe nitrate pollution and health risks of coastal aquifer simultaneously influenced by saltwater intrusion and intensive anthropogenic activities. Arch. Environ. Contam. Toxicol. 77, 79-87.

Xu, Y., Luo, F., Pal, A., Gin, K.Y.-H., 2011. Martin Reinhard. Occurrence of emerging organic contaminants in a tropical urban catchment in Singapore. Chemosphere 83, 963-969.

Ying, G.-G., Kookana, R.S., Kumar, A., Mortimer, M., 2009. Occurrence and implications of estrogens and xenoestrogens in sewage effluents and receiving waters from South East Queensland. Sci. Total Environ. 407, 5147-5155.

Zhao, J.-L., Ying, G.-G., Chen, F., Liu, Y.-S., Wang, L., Yang, B., Liu, S., Tao, R., 2011 Estrogenic activity profiles and risks in surface waters and sediments of the Pearl River system in South China assessed by chemical analysis and in vitro bioassay. J. Environ. Monit. 13, 813-821.

Zhu, Y.G., Zhao, Y., Li, B., Huang, C.L., Zhang, S.Y., Yu, S., Chen, Y.Y., Zhang, T., 2017 Continental-scale pollution of estuaries with antibiotic resistance genes. Nat. Microbiol. 2, 16270 . 